\title{
S.I.Ovcharenko, Yu.K.Galetskayte, B.A.Volel \\ Predictors of disadaptive disorders in patients with chronic obstructive pulmonary disease
}

\begin{abstract}
Summary
Anxiety and depression in patients with chronic obstructive pulmonary disease (COPD) could be considered as comorbidity or disadaptive response to the disease. Besides widespread anxiety and depression in COPD patients, another behavioral disorder has been described which is hyponosognosia (aberrant hypochondria).

The aim of this study was to investigate prevalence of different types of psychological responses to the disease and their relations to COPD course and sociodemographic parameters. The study involved 95 COPD patients ( 77 males) aged $66.7 \pm 7.7$ years. Three types of psychological responses have been observed: trouble for health $(n=31 ; 32.6 \%)$, depression $(n=10 ; 10.5 \%)$, hyponosognosia $(n=44 ; 46.4 \%)$. Groups of patients with trouble for health and depression were similar and consequently were jointed in a single group $(n=41)$ which was compared to hyponosognosia group $(n=44)$. This comparison allowed discover several predictors of disadaptive responses that could be presumably used by a therapeutist to predict and treat disadaptive behavior in COPD patients.

Key words: chronic obstructive pulmonary disease, anxiety, depression, hyponosognosia (aberrant hypochondria), disadaptive response to the disease, behavior.
\end{abstract}

\section{Резюме}

Тревожно-депрессивные расстройства при хронической обструктивной болезни легких (ХОБЛ) могут рассматриваться с точек зрения как сопутствующей патологии, так и дезадаптивных типов реагирования на заболевание. Помимо большой распространенности тревоги и депрессии, имеются данные о наличии другого - полярного типа поведения в болезни - гипонозогнозии (аберрантной ипохондрии). Изучалась частота встречаемости и характеристики различных типов реагирования на болезнь с определением соотношения между выявленными типами реагирования и особенностями течения ХОБЛ, а также социодемографическими показателями.

Обследованы больные ХОБЛ ( $n=95 ; 77$ мужчин, 18 женщин; средний возраст $-66,7 \pm 7,7$ года), среди которых выявлено 3 типа реагирования на болезнь: тревога о болезни - у 31 (32,6 \%), депрессия - у $10(10,5 \%)$, гипонозогнозия - у 44 (46,4 \%) пациентов. Показана сопоставимость больных с тревогой и депрессией, на основании чего они были объединены в одну группу (группа $\mathrm{A}, n=41)$ для сравнения с пациентами с гипонозогнозей (группа $\mathrm{B}, n=44)$. При сопоставлении характеристик пациентов 2 групп и особенностей течения ХОБЛ у них выявлен ряд отличающихся параметров - предикторов формирования дезадаптивных типов реагирования, на основании которых врач-терапевт, предположительно, без помощи психиатра сможет прогнозировать возникновение и проводить коррекцию дезадаптивных черт поведения в болезни, влияющих как на приверженность лечению, так и прогноз заболевания.

Ключевые слова: хроническая обструктивная болезнь легких, тревога и депрессия, гипонозогнозия (аберрантная ипохондрия), дезадаптивные типы реагирования на болезнь, поведение в болезни.

Хроническая обструктивная болезнь легких (ХОБЛ), являясь болезнью пожилого человека (диагноз правомочен у лиц старше 40 лет), в большинстве случаев сочетается с заболеваниями других органов и систем. В последних редакциях основного документа по менеджменту ХОБЛ - Глобальной стратегии диагностики, лечения и профилактики ХОБЛ (GOLD 2011, 2013, 2014) - постоянно подчеркивается роль сопутствующих / сочетанных заболеваний / состояний и их вклад в тяжесть и прогноз ХОБЛ [1]. Среди большого количества сопутствующих заболеваний одно из ведущих мест принадлежит психическим расстройствам (ПР), которые выявляются у $8-35 \%$ пациентов [2]. Достаточное внимание уделяется тревоге и депрессии, которые ассоциированы со значительным ухудшением прогноза и снижением качества жизни. Они включены в пятерку самых значимых сопутствующих заболеваний наряду с сердечно-со- судистой патологией, остеопорозом, раком легких, метаболическим синдромом и сахарным диабетом.

Жалобы больного ХОБЛ не всегда полностью соответствуют тяжести заболевания. Некоторые из них могут быть только частично обусловлены его физическим неблагополучием, а в определенной мере служить проявлениями аффективных и мыслительных нарушений. Основной жалобой больных ХОБЛ является одышка, однако в сочетании с чувством витального страха она может рассматриваться как проявление ПР. С другой стороны, проявления ХОБЛ самостоятельно могут вызывать психический и поведенческий ответ, увеличивающий степень выраженности проявлений самой болезни по оценке пациента [3]. Все перечисленное - потенциальная основа формирования дезадаптивных типов реагирования при ХОБЛ, к которым в первую очередь относятся тревога и депрессия. 
При изучении тревожно-депрессивных расстройств (ТДР) эти нарушения устанавливаются при использовании только опросников, заполняемых самими пациентами. Судя по литературным данным, это может приводить и приводит к большому разбросу распространенности тревоги и депрессии у больных ХОБЛ [4-6]. Отличный от тревоги и депрессии дезадаптивный тип реагирования при ХОБЛ отмечен лишь в 1 исследовании [7], в котором, в противоположность тревоге и депрессии, у $50 \%$ больных ХОБЛ выявлено отсутствие какой-либо свойственной больным с ТДР эмоциональной реакции на имеющийся телесный недуг. Этот тип реагирования на болезнь обозначается психологами как гипонозогнозия [8], психиатрами - аберрантная ипохондрия [9]. Под гипонозогнозией (аберратнтной ипохондрией) понимается дефицитарный тип реагирования на заболевание, при котором отсутствует минимальная эмоциональная реакция на возникшую соматическую патологию (ХОБЛ), что сопровождается неадекватным поведением при выполнении медицинских предписаний. В то же время у пациентов с гипонозогнозией не регистрируются какие-либо ассоциированные с соматическим заболеванием позитивные психопатологические расстройства - депрессия или тревога о болезни [9].

Целью работы явилось изучение частоты встречаемости и характеристики различных типов реагирования на болезнь с определением соотношения между выявленными типами реагирования с одной стороны и особенностями течения ХОБЛ и социодемографическими показателями - с другой.

\section{Материалы и методы}

Исследование выполнено при совместном участии сотрудников кафедры факультетской терапии № 1, кафедры психиатрии и психосоматики ФППОВ на базе межклинического психосоматического отделения ГБОУ "Первый МГМУ им. И.М.Сеченова". Протокол исследования одобрен Межвузовским комитетом по этике при Ассоциации медфармвузов России. От всех пациентов получено добровольное информированное согласие на участие в исследовании.

Набор материала проводился на базе терапевтического отделения Клиники факультетской терапии им. В.Н.Виноградова и пульмонологического кабинета в составе Лечебно-диагностического отделения № 1 Университетской клинической больницы № 1 ГБОУ "Первый МГМУ им. И.М.Сеченова" среди пациентов, получавших стационарное и амбулаторное лечение.

Критерии включения в исследование:

- возраст от 40 до 80 лет;

- установленный диагноз ХОБЛ легкого, среднетяжелого, тяжелого и крайне тяжелого течения (GOLD, 2008);

- длительность ХОБЛ $\geq 2$ лет, что соответствует срокам формирования ипохондрического развития как одного из способов реагирования на соматическое заболевание, установленное Б.А.Волель [6].
Критерии исключения из исследования:

- возраст моложе 40 и старше 80 лет;

- декомпенсация сопутствующих заболеваний и явления выраженной дыхательной недостаточности при крайне тяжелом течении ХОБЛ на момент исследования, что делает невозможным интервьюирование пациента;

- актуальное злокачественное новообразование на момент обследования;

- наличие ПР:

- шизофрения (параноидная, гебефреническая, кататоническая), хроническая бредовая, острые психотические, шизоаффективные расстройства;

- биполярное аффективное расстройство, текущий маниакальный эпизод с психотическими симптомами;

- органическое ПР (деменция при болезни Альцгеймера, сосудистая деменция; деменция при других болезнях, классифицированных в других рубриках; деменция неуточненная; органический амнестический синдром; делирий, вызванный не алкоголем или другими психоактивными веществами; органический галлюциноз; органическое кататоническое состояние; органическое бредовое шизофреноподобное расстройство);

- ПР и расстройство поведения, связанное с употреблением психоактивных веществ; острая интоксикация; абстинентное состояние с делирием; психотическое расстройство; амнестический синдром.

Bсе пациенты были подвергнуты полноценному клинико-лабораторному и инструментальному обследованию. Больные отвечали на ряд вопросов, оценивающих как клинические проявления ХОБЛ, так и выраженность тревоги и депрессии. Использовались визуальная аналоговая шкала (ВАШ) одышки, оценочный тест ХОБЛ (COPD Assessment Test - CAT), модифицированная шкала одышки (mMRC), шкала депрессии Бэка (Beck Depression Inventory - BDI), госпитальная шкала тревоги и депрессии (Hospital Anxiety and Depression Scale - HADS). В дальнейшем больные консультировались мультидисциплинарной группой специалистов, состоявшей из пульмонолога, психиатра и клинического психолога.

В выборку включены больные ХОБЛ $(n=95$; 77 мужчин, 18 женщин $(4,3: 1,0)$; средний возраст $66,7 \pm 7,7$ года; длительность ХОБЛ $-5,2 \pm 3,6$ года, индекс курящего человека (ИКЧ) $-49,4 \pm 24,5$ пачко-лет).

Среднетяжелое течение заболевания отмечено в $48(50,5 \%)$ случаях, тяжелое - в 33 (34,8 \%). Крайне тяжелое течение ХОБЛ выявлено у 12 (12,6 \%) пациентов, легкое - у 2 (2,1\%).

\section{Результаты и обсуждение}

При распределении различных типов реагирования на ХОБЛ (рис. 1) отмечено, что адекватное реагирование на болезнь определено лишь у 10 (10,5 \%) пациентов. 


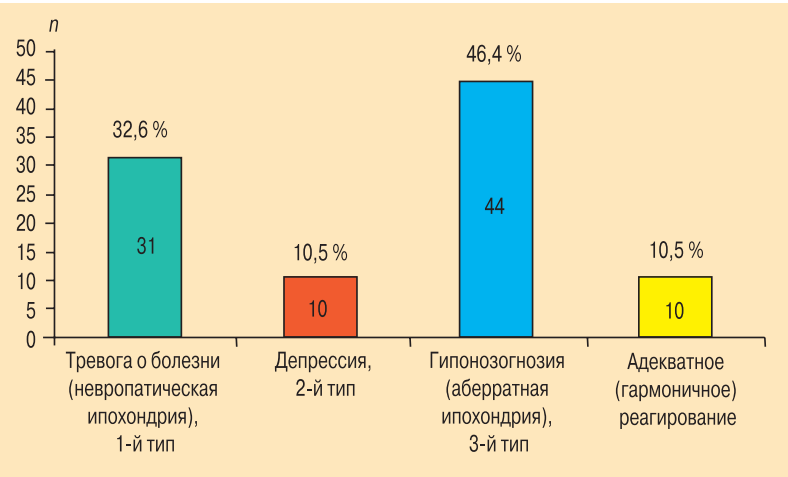

Рис. 1. Распределение различных типов реагирования при ХОБЛ
Помимо хорошо изученных при ХОБЛ тревоги (1-й тип), диагностированной в 31 (32,6 \%) случае, и депрессии (2-й тип) - у 10 (10,5\%) больных, у $44(46,4 \%)$ пациентов был выявлен полярный (дезадаптивный) тип реагирования - гипонозогнозия (3-й тип).

В зарубежной литературе понятия тревоги и депрессии объединяются и рассматриваются ее как единое целое [5, 6]. Такое объединение обусловлено сходством 2 типов реагирования. Так, в повседневной жизни под термином "тревога" понимается эмоциональное переживание, характеризующееся дискомфортом от неизвестности перспективы и имеющее определенный биологический смысл - мобилиза-

Таблища 1 Сопоставление пациентов с тревогой о болезни и депрессией по демографическим характеристикам

\begin{tabular}{|c|c|c|c|}
\hline \multirow[t]{2}{*}{ Критерий } & 1-й тип & 2-й тип & $p$ \\
\hline & тревога о болезни $(n=31)$ & депрессия $(n=10)$ & 1-й тип vs 2-го типа \\
\hline \multicolumn{4}{|l|}{ Пол, $n$ (\%): } \\
\hline мужской & $24(77,4)$ & $6(60)$ & 0,246 \\
\hline женский & $7(22,6)$ & $4(40)$ & 0,246 \\
\hline Возраст, годы, $m \pm S D$ & $67,200 \pm 7,649$ & $69,400 \pm 3,893$ & 0,242 \\
\hline \multicolumn{4}{|l|}{ Образование, $n$ (\%): } \\
\hline среднее & $4(12,9)$ & $1(10,0)$ & 0,647 \\
\hline среднее специальное & $10(32,3)$ & $2(20,0)$ & 0,378 \\
\hline высшее & $17(54,8)$ & $7(70,0)$ & 0,321 \\
\hline Работающие, $n$ (\%) & $6(19,4)$ & $2(20,0)$ & 0,642 \\
\hline Инвалиды, $n$ (\%) & $18(58,1)$ & $4(40,0)$ & 0,264 \\
\hline Длительность инвалидности, годы & $7,600 \pm 4,227$ & $7,800 \pm 5,058$ & 0,967 \\
\hline \multicolumn{4}{|l|}{ Группа инвалидности, $n$ (\%): } \\
\hline нет & $13(41,9)$ & $6(60,0)$ & 0,264 \\
\hline 1 & $2(6,5)$ & $1(10,0)$ & 0,578 \\
\hline II & $15(48,4)$ & $3(30,0)$ & 0,259 \\
\hline III & $1(3,2)$ & $0(0)$ & 0,756 \\
\hline ИМТ, кг / M² $( \pm S D)^{2}$ & $27,400 \pm 5,965$ & $26,900 \pm 7,959$ & 0,858 \\
\hline \multicolumn{4}{|l|}{ Питательный статус, $n$ (\%): } \\
\hline пониженный & $2(6,4)$ & $2(20,0)$ & 0,245 \\
\hline нормальный & $14(45,2)$ & $3(30,0)$ & 0,321 \\
\hline избыточный & $7(22,6)$ & $2(20,0)$ & 0,620 \\
\hline ожирение & $8(25,8)$ & $3(30,0)$ & 0,546 \\
\hline
\end{tabular}

Примечание: ИМТ - индекс массы тела.

Таблица 2

Сопоставление пациентов с тревогой о болезни и депрессией по факторам, предрасполагающим к развитию ХОБЛ

\begin{tabular}{|c|c|c|c|}
\hline \multirow[t]{2}{*}{ Критерий } & 1-й тип & 2-й тип & $p$ \\
\hline & тревога о болезни, $n=31$ & депрессия, $n=10$ & 1-й тип vs 2-го типа \\
\hline Курение как предрасполагающий фактор, n (\%) & $28(90,3)$ & $10(100,0)$ & 0,422 \\
\hline Длительность курения, годы ( \pm SD) & $42,800 \pm 8,969$ & $47,700 \pm 9,923$ & 0,159 \\
\hline Количество выкуриваемых сигарет в сутки ( \pm SD) & $19,600 \pm 7,961$ & $20,000 \pm 4,714$ & 0,890 \\
\hline ИКЧ, пачко-лет ( \pm SD) & $41,600 \pm 17,584$ & $48,400 \pm 16,142$ & 0,293 \\
\hline Курение на момент включения в исследование, $n$ (\%) & $11(35,5)$ & $6(60,0)$ & 0,159 \\
\hline Попытки бросить курить в анамнезе, $n$ (\%) & $27(96,4)$ & $6(60)$ & 0,082 \\
\hline Наличие профессиональных вредностей, $n$ (\%) & $12(38,7)$ & $3(30,0)$ & 0,46 \\
\hline Частые ОРЗ в анамнезе, $n$ (\%) & $17(54,8)$ & $4(40,0)$ & 0,326 \\
\hline
\end{tabular}

Примечание: ОРЗ - острое респираторное заболевание. 
ции ресурсов организма, обеспечивающих поведение в экстремальных состояниях.

Тревога расценивается как патологическая и относится к категории ПР лишь при нарушении повседневной активности [10]. Одним из видов тревоги в области психосоматической медицины является тревога о болезни, которая в психиатрической терминологии соответствует термину "невротическая ипохондрия". Под термином "тревога о болезни" понимаются неадекватные или чрезмерные опасения, базирующиеся на необоснованном восприятии телесных ощущений (как опасных и / или сигнализирующих о соматическом заболевании), приводящие к дистрессу [9]. Она может также проявляться в виде панических атак и соматовегетативных нарушений.

Всемирная организация здравоохранения дает следующее определение депрессии: "Депрессия - это распространенное ПР, для которого характерны уныние, потеря интереса или радости, чувство вины и низкая самооценка, нарушения сна или аппетита, вялость и плохая концентрация внимания" [11]. Академик РАМН А.Б.Смулевич расширяет определение депрессии, акцентируя внимание на таких характерных чертах депрессии, как патологически сниженное настроение (гипотимия), негативная пессимистическая самооценка себя, своего положения в окружающей действительности и своего будущего, искажение мыслительных процессов, моторное торможение, снижение побуждений к деятельности, соматовегетативные дисфункции [12]. В этом определении прослеживается описание эмоциональных черт, общих с тревогой.

С целью оценки имеющегося сходства и различий в характеристике больных с этими 2 типами реагирования проведено сопоставление пациентов с тревогой о болезни (1-й тип) и депрессией (2-й тип). Сопоставление особенностей больных ХОБЛ с тревогой и депрессией проводилось по полностью сопоставимым демографическим показателям (табл. 1), предрасполагающим факторам развития ХОБЛ (табл. 2), характеристикам течения ХОБЛ (табл. 3), сопутствующим

Таблица 3

Сопоставление пациентов с тревогой о болезни и депрессией по основным характеристикам ХОБЛ

\begin{tabular}{|c|c|c|c|}
\hline \multirow[t]{2}{*}{ Критерий } & 1-й тип & 2-й тип & $p$ \\
\hline & тревога о болезни, $n=31$ & депрессия, $n=10$ & 1-й тип vs 2-го типа \\
\hline Длительность ХОБЛ, годы & $6,800 \pm 4,866$ & $4,100 \pm 2,183$ & 0,019 \\
\hline Длительность одышки до установления диагноза, годы & $1,800 \pm 4,193$ & $5,800 \pm 7,554$ & 0,141 \\
\hline \multicolumn{4}{|l|}{ Одышка по mMRC в баллах, $n$ (\%): } \\
\hline 1 & $2(6,5)$ & $1(10)$ & 0,578 \\
\hline 2 & $13(41,9)$ & $3(30)$ & 0,388 \\
\hline 3 & $13(41,9)$ & $5(50)$ & 0,465 \\
\hline 4 & $3(9,7)$ & $1(10)$ & 0,689 \\
\hline $\begin{array}{l}\text { Разность между оценкой одышки больным (во ВАШ) } \\
\text { и врачом(по шкале } \mathrm{mMRC}) M \pm S D\end{array}$ & $-0,871 \pm 0,718$ & $-0,600 \pm 0,516$ & 0,278 \\
\hline \multicolumn{4}{|l|}{ Преобладание, $n$ (\%): } \\
\hline эмфиземы & $11(35,5)$ & $7(70)$ & 0,061 \\
\hline бронхита & $7(22,6)$ & $2(10)$ & 0,620 \\
\hline ОФВ 1 постбронходилатационный, \%, M \pm SD & $52,400 \pm 16,775$ & $54,500 \pm 14,993$ & 0,737 \\
\hline \multicolumn{4}{|l|}{$\begin{array}{l}\text { Стадия ХОБЛ (GOLD, 2008) или степень ограничения бронхиальной } \\
\text { проходимости (GOLD, 2011), n (\%): }\end{array}$} \\
\hline I (легкая) & $0(0,0)$ & $0(0)$ & 0 \\
\hline II (среднетяжелая) & $15(48,4)$ & $8(80)$ & 0,081 \\
\hline III (тяжелая) & $11(35,5)$ & $1(10)$ & 0,125 \\
\hline IV (крайне тяжелая) & $5(16,1)$ & $1(10)$ & 0,542 \\
\hline Частота обострений в год, $M \pm$ SD & $1,950 \pm 0,907$ & $2,150 \pm 1,492$ & 0,613 \\
\hline Число пациентов, имеющих $\geq 2$ обострений в год & $18(58,1)$ & $6(60)$ & 0,606 \\
\hline Сатурация кислородом, \% \pm SD & $93,400 \pm 3,101$ & $94,100 \pm 4,776$ & 0,605 \\
\hline Число умерших больных за время проведения исследования, $n$ (\%) & $0(0,0)$ & $1(10)$ & 0,244 \\
\hline
\end{tabular}

Примечание: ОФВ 1 - объем форсированного выдоха за 1-ю секунду.

Таблица 4

Сопоставление пациентов с тревогой о болезни и депрессией по сопутствующей патологии, $n$ (\%)

\begin{tabular}{|c|c|c|c|}
\hline \multirow[t]{2}{*}{ Критерий } & 1-й тип & 2-й тип & $p$ \\
\hline & тревога о болезни, $n=31$ & депрессия, $n=10$ & 1-й тип vs 2-го типа \\
\hline Сочетание с БА & $8(25,8)$ & $6(60)$ & 0,057 \\
\hline Облитерирующий склероз нижних конечностей & $6(19,4)$ & $3(30)$ & 0,379 \\
\hline ИБС & $14(45,2)$ & $0(0)$ & 0,008 \\
\hline ИМ в анамнезе & $6(19,4)$ & $0(0)$ & 0,164 \\
\hline $\mathrm{XCH}$ & $10(32,3)$ & $1(10,0)$ & 0,167 \\
\hline ОНМК в анамнезе & $3(9,7)$ & $0(0)$ & 0,421 \\
\hline
\end{tabular}

Примечание: ИБС - ишемическая болезнь сердца; ИМ - инфаркт миокарда; ХСН - хроническая сердечная недостаточность; ОНМК - острое нарушение мозгового кровообращения. 
Сопоставление пациентов с тревогой о болезни и депрессией по степени выполнения лечебной программы (до включения в исследование), $n$ (\%)

\begin{tabular}{|c|c|c|c|}
\hline \multirow[t]{2}{*}{ Критерий } & 1-й тип & 2-й тип & $p$ \\
\hline & тревога о болезни, $n=31$ & депрессия, $n=10$ & 1-й тип vs 2-го типа \\
\hline Прием системных ГКС & $9(29,0)$ & $1(10)$ & 0,219 \\
\hline \multicolumn{4}{|l|}{ Применяемые препараты: } \\
\hline бронхолитики короткодействующие & $7(22,6)$ & $3(30,0)$ & 0,464 \\
\hline бронхолитики длительно действующие & $4(12,9)$ & $0(0)$ & 0,311 \\
\hline бронхолитики короткодействующие + иГКС & $4(12,9)$ & $0(0)$ & 0,311 \\
\hline бронхолитики длительно действующие + иГКС & $10(32,3)$ & $7(70,0)$ & 0,042 \\
\hline небулайзерная терапия & $6(19,4)$ & $0(0)$ & 0,164 \\
\hline Пикфлуометрия & $16(51,6)$ & $5(50)$ & 0,607 \\
\hline Дыхательная гимнастика & $14(45,2)$ & $5(50)$ & 0,537 \\
\hline \multicolumn{4}{|c|}{ Степень приверженности лечению по оценке эксперта-пульмонолога: } \\
\hline низкая & $3(9,7)$ & $0(0)$ & 0,422 \\
\hline средняя & $13(41,9)$ & $5(50)$ & 0,465 \\
\hline высокая & $15(48,4)$ & $5(50)$ & 0,607 \\
\hline
\end{tabular}

заболеваниям (табл. 4) и факторам, определяющим приверженность пациентов лечению (табл. 5).

Предрасполагающие факторы и большинство особенностей течения ХОБЛ у пациентов с 1-м и 2-м типами реагирования не различались. Длительность заболевания при обоих типах была разная (см. табл. 3): при депрессии длительность ХОБЛ меньше, чем при тревоге о болезни. Это можно объяснить большим накоплением больных бронхиальной астмой (БА) среди пациентов с депрессией (см. табл. 4), при наличии которой диагностика ХОБЛ значительно затруднена.

БА требовала назначения ингаляционных глюкокортикостероидов (иГКС) в сочетании с длительно действующими бронхолитиками, что объясняет большую распространенность этой схемы лечения среди больных с депрессией (см. табл. 5).

Исходя из представленных данных о несущественных различиях между пациентами с тревогой о болезни и депрессией, для сравнения с противоположным типом поведения в болезни - гипонозогнозией - пациенты с тревогой и депрессией были объединены в общую группу (группа А); больные с гипонозогнозией отнесены к группе В.
При изучении поведения в болезни у пациентов с ХОБЛ при тревоге и депрессии (группа А) внимание акцентировалось на основных особенностях таких больных [13]: у пациентов с тревогой и депрессией настроение напрямую зависит от состояния их здоровья, они делают все, чтобы улучшить его. Больные не только бросают курить и уходят с вредного производства, но и формируют вокруг себя охранительный щадящий режим. Как правило, они имеют высокий комплаенс, заинтересованы в получении информации о собственном заболевании, выполняют все рекомендации врача, однако в связи с обостренным чувством самонаблюдения у них нередко возникает ожидание появления побочных эффектов. Такие пациенты из-за боязни развития нежелательных явлений склонны самостоятельно снижать дозу препаратов, особенно часто - иГКС. Чтобы избежать нарушения режима дозирования препарата пациентом, врачу следует при ведении таких больных обстоятельно объяснять его механизмы действия, некоторые аспекты фармакокинетики лекарственных средств, нежелательные явления и вероятность их возникновения при правильном применении препарата.

Таблица 6

Сравнение групп по степени выполнения лечебной програлмы (до включения в исследование)

\begin{tabular}{|c|c|c|c|}
\hline \multirow[t]{2}{*}{ Критерий } & Группа В & Группа A & $p$ \\
\hline & гипонозогнозия, $n=44$ & тревога и депрессия, $n=41$ & группа A vs группы B \\
\hline Прием системных ГКС, $n$ (\%): & $8(18,2)$ & $10(24,4)$ & 0,332 \\
\hline бронхолитики короткодействующие & $22(50,0)$ & $10(24,4)$ & 0,013 \\
\hline бронхолитики длительно действующие & $6(13,6)$ & $4(9,8)$ & 0,416 \\
\hline бронхолитики короткодействующие + иГКС & $2(4,5)$ & $4(9,8)$ & 0,305 \\
\hline бронхолитики длительно действующие + иГКС & $10(22,7)$ & $17(41,4)$ & 0,180 \\
\hline небулайзерная терапия & $4(9,1)$ & $6(14,6)$ & 0,324 \\
\hline Выполнение пикфлуометрии, $n$ (\%) & $2(4,5)$ & $21(51,2)$ & 0,000 \\
\hline Занятия дыхательной гимнастикой, $n$ ( (\%) & $0(0,0)$ & $19(46,3)$ & 0,000 \\
\hline \multicolumn{4}{|c|}{$\begin{array}{l}\text { Степень приверженности лечению по оценке эксперта- } \\
\text { пульмонолога, } n \text { ( (\%): }\end{array}$} \\
\hline низкая & $35(79,5)$ & $3(7,3)$ & 0,000 \\
\hline средняя & $9(20,5)$ & $18(43,9)$ & 0,018 \\
\hline высокая & $0(0,0)$ & $20(48,8)$ & 0,000 \\
\hline
\end{tabular}


В противоположность лицам с тревогой и депрессией пациенты с гипонозогнозией (группа В) склонны недооценивать тяжесть своего состояния, а порой и вовсе игнорировать имеющиеся симптомы и возможное прогрессирование заболевания. Они продолжают курить, остаются на вредном производстве, не заинтересованы в получении информации о заболевании, не принимают регулярно препараты [13]. Как правило, такие больные заинтересованы лишь в немедленном улучшении своего самочувствия, чем и объясняется зачастую прием только бронхолитиков короткого действия с быстрым развитием эффекта. Такие больные в большинстве случаев не выполняют упражнения дыхательной гимнастики, не контролируют состояние бронхиальной проходимости, что определяет крайне низкую комплаентность (табл. 6).
При сравнении поведения в болезни пациентов групп А и В выявлены явные различия. Также показаны различия у пациентов этих 2 групп не только в поведении при болезни, но и социодемографических показателей (табл. 7) по факторам, предрасполагающим к развитию ХОБЛ, выявляются более выраженные различия (табл. 8) и основные особенности ее течения (табл. 9) при сопутствующих заболеваниях (рис. 2). На основании сравнительного анализа этих показателей выявлены предикторы дезадаптивных типов реагирования с целью предоставления лечащему врачу инструмента для раннего прогнозирования возникновения дезадаптивных черт и возможной их коррекции.

У больных с гипонозогнозией отмечались более низкий уровень образования и возраст, чем у пациентов с тревогой и депрессией. Несмотря на сопоставимые показатели трудоспособности, в группе

таблица 7

Сравнение групп пациентов по социодемографическим характеристикам

\begin{tabular}{|c|c|c|c|c|c|}
\hline \multirow[t]{2}{*}{ Критерий } & \multirow{2}{*}{$\begin{array}{c}\text { Группа В } \\
\text { гипонозогнозия, } n=44\end{array}$} & \multirow{2}{*}{$\begin{array}{c}\text { Группа А } \\
\text { тревога и депрессия, } n=41\end{array}$} & \multicolumn{3}{|c|}{$p$} \\
\hline & & & $\begin{array}{l}\text { группа B } \\
\text { vs группы A }\end{array}$ & $\begin{array}{l}\text { группа B } \\
\text { vs } 1 \text {-го типа }\end{array}$ & $\begin{array}{c}\text { группа В } \\
\text { vs } 2 \text {-го типа }\end{array}$ \\
\hline \multicolumn{6}{|l|}{ Пол, $\boldsymbol{n}(\%):$} \\
\hline мужской & $37(84,1)$ & $30(73,2)$ & 0,167 & 0,331 & 0,105 \\
\hline женский & $7(15,9)$ & $11(26,8)$ & 0,167 & 0,331 & 0,105 \\
\hline Возраст, годы, $M \pm S D$ & $64,6 \pm 8,417$ & $67,8 \pm 6,942$ & 0,0003 & 0,178 & 0,024 \\
\hline \multicolumn{6}{|l|}{ Образование, $n$ (\%): } \\
\hline среднее & $12(27,3)$ & $5(12,2)$ & 0,070 & 0,112 & 0,237 \\
\hline среднее специальное & $16(36,4)$ & $12(29,3)$ & 0,322 & 0,453 & 0,275 \\
\hline высшее & $16(36,4)$ & $24(58,5)$ & 0,033 & 0,088 & 0,057 \\
\hline Работающие, $n$ (\%) & $19(43,2)$ & $8(19,5)$ & 0,017 & 0,027 & 0,160 \\
\hline Инвалиды, $n$ (\%) & $22(50,0)$ & $22(53,7)$ & 0,452 & 0,325 & 0,414 \\
\hline Длительность инвалидности, годы & $6,110 \pm 5,648$ & $7,670 \pm 4,258$ & 0,876 & 0,881 & 0,957 \\
\hline \multicolumn{6}{|l|}{ Группа инвалидности, $n$ (\%): } \\
\hline нет & $22(50,0)$ & $19(46,3)$ & 0,452 & 0,325 & 0,414 \\
\hline 1 & $0(0,0)$ & $3(7,3)$ & 0,108 & 0,168 & 0,185 \\
\hline II & $17(38,6)$ & $18(43,9)$ & 0,393 & 0,273 & 0,450 \\
\hline III & $5(11,4)$ & $1(2,4)$ & 0,118 & 0,202 & 0,343 \\
\hline ИMT, $\mathrm{kr} / \mathrm{M}^{2}( \pm S D)$ & $27,500 \pm 5,039$ & $27,300 \pm 6,233$ & 0,893 & 0,947 & 0,805 \\
\hline \multicolumn{6}{|l|}{ Питательный статус, $n$ (\%): } \\
\hline пониженный & $4(9,1)$ & $4(9,8)$ & 0,603 & 0,516 & 0,306 \\
\hline нормальный & $13(29,5)$ & $17(41,5)$ & 0,211 & 0,159 & 0,636 \\
\hline избыточный & $16(36,4)$ & $9(21,9)$ & 0,111 & 0,154 & 0,275 \\
\hline ожирение & $11(20,5)$ & $11(26,8)$ & 0,521 & 0,574 & 0,399 \\
\hline
\end{tabular}

Таблица 8

Сравнение групп пациентов по факторам, предрасполагающил к развитию ХОБЛ

\begin{tabular}{|c|c|c|c|c|c|}
\hline \multirow[t]{2}{*}{ Критерий } & \multirow{2}{*}{$\begin{array}{c}\text { Группа В } \\
\text { гипонозогнозия, } \\
n=44\end{array}$} & \multirow{2}{*}{$\begin{array}{c}\text { Группа A } \\
\begin{array}{c}\text { тревога и депрессия, } \\
n=41\end{array}\end{array}$} & \multicolumn{3}{|c|}{$p$} \\
\hline & & & $\begin{array}{c}\text { группа B } \\
\text { vs группы A }\end{array}$ & $\begin{array}{c}\text { группа В } \\
\text { vs } 1 \text {-го типа }\end{array}$ & $\begin{array}{c}\text { группа В } \\
\text { vs } 2 \text {-го типа }\end{array}$ \\
\hline Курение как предрасполагающий фактор, $n$ (\%) & $41(93,2)$ & $38(92,7)$ & 0,628 & 0,484 & 0,534 \\
\hline Длительность курения, годы ( \pm SD) & $44,500 \pm 12,438$ & $44,100 \pm 9,349$ & 0,878 & 0,544 & 0,451 \\
\hline Количество выкуриваемых сигарет в сутки (N \pm SD) & $26,600 \pm 10,652$ & $19,700 \pm 7,189$ & 0,001 & 0,003 & 0,005 \\
\hline ИКЧ, пачко-лет ( $\pm S D)$ & $58,200 \pm 27,932$ & $43,400 \pm 17,267$ & 0,006 & 0,007 & 0,289 \\
\hline Курение на момент включения в исследование, $n$ (\%) & $30(68,2)$ & $17(41,5)$ & 0,012 & 0,005 & 0,440 \\
\hline Попытки бросить курить в анамнезе, $n$ (\%) & $20(45,5)$ & $33(80,5)$ & 0,0008 & 0,0002 & 0,316 \\
\hline Наличие профессиональных вредностей, $n$ (\%) & $24(54,5)$ & $15(36,6)$ & 0,074 & 0,132 & 0,147 \\
\hline Частые ОР3, n (\%) & $11(25,0)$ & $21(51,2)$ & 0,011 & 0,008 & 0,278 \\
\hline
\end{tabular}




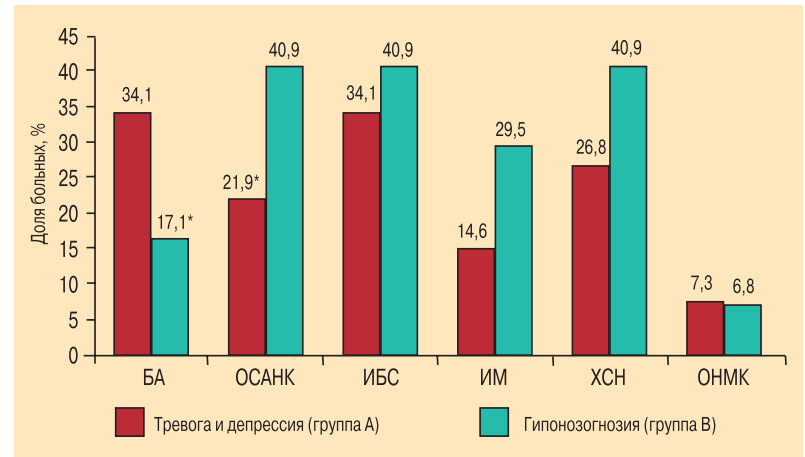

Рис. 2. Сопутствующие заболевания

Примечание: ОСАНК - облитерирующий склероз артерий нижних конечностей; ${ }^{*}-p<0,05$.

гипонозогнозии было больше работающих пациентов.

Большинство больных в группе гипонозогнозии были злостными курильщиками с большим ИКЧ, отсутствием в анамнезе даже попыток отказа от курения и продолжающие курить на момент исследования.

По сравнению с группой тревоги в группе гипонозогнозии было немного больше пациентов с профессиональными вредностями и значительно меньше - с указанием на ОРЗ в анамнезе.

Длительность ХОБЛ в группе В была значимо меньше, однако у них длительное время наблюдались симптомы со стороны органов дыхания до об- ращения к врачу и установления диагноза. Эти больные чаще описывали свою одышку в соответствии c 1 баллом по шкале mMRC. При сравнении средних показателей разницы между оценкой одышки самим пациентом (BAШ) и врачом (mMRC) в группе гипонозогнозии отмечалась тенденция к меньшей величине различий. Среди больных с гипонозогнозией чаще встречались пациенты с преимущественно бронхитическим фенотипом ХОБЛ, в то время как в группе тревоги и депрессии - преимущественно эмфизематозным. Большинство пациентов с гипонозогнозией указывали на $<2$ обострения в год.

В группе гипонозогнозии редко встречались больные с сочетанием ХОБЛ и БА, в отличие от больных с тревогой и депрессией (см. рис. 2). Среди больных с гипонозогнозией значимо чаще встречались пациенты с сопутствующим поражением артерий нижних конечностей. Распространенность ИБС в 2 группах была одинаковой, однако больные с гипонозогнозией чаще имели уже перенесенный острый ИМ в анамнезе.

Основные отличия пациентов с тревогой и депрессией от пациентов с гипонозогнозией представлены в табл. 10. Они могут рассматриваться и как основные предикторы формирования полярных дезадаптивных типов реагирования при ХОБЛ.

Таким образом, используя перечисленные характеристики, специалист в области внутренних болез-

Таблица 9

Сравнение групп пащиентов по основным характеристикал ХОБЛ

\begin{tabular}{|c|c|c|c|c|c|}
\hline \multirow[t]{2}{*}{ Критерий } & \multirow{2}{*}{$\begin{array}{c}\text { Группа В } \\
\text { гипонозогнозия, } \\
n=44\end{array}$} & \multirow{2}{*}{$\begin{array}{c}\text { Группа A } \\
\text { тревога и депрессия, } \\
n=41\end{array}$} & \multicolumn{3}{|c|}{$p$} \\
\hline & & & $\begin{array}{l}\text { группа B } \\
\text { vs группы A }\end{array}$ & $\begin{array}{l}\text { группа B } \\
\text { vs } 1 \text {-го типа }\end{array}$ & $\begin{array}{l}\text { группа B } \\
\text { vs 2-го типа }\end{array}$ \\
\hline Длительность ХОБЛ, годы & $4,400 \pm 2,605$ & $6,2 \pm 4,5$ & 0,031 & 0,015 & 0,739 \\
\hline Длительность одышки до установления диагноза, годы & $5,800 \pm 8,933$ & $2,700 \pm 5,387$ & 0,056 & 0,011 & 0,979 \\
\hline \multicolumn{6}{|l|}{ Одышка по mMRC, баллы, $n$ (\%): } \\
\hline 1 & $10(22,7)$ & $3(7,3)$ & 0,046 & 0,054 & 0,339 \\
\hline 2 & $9(20,5)$ & $16(39,0)$ & 0,05 & 0,04 & 0,389 \\
\hline 3 & $20(45,5)$ & $18(43,9)$ & 0,53 & 0,474 & 0,533 \\
\hline 4 & $5(11,4)$ & $4(9,8)$ & 0,546 & 0,565 & 0,694 \\
\hline $\begin{array}{l}\text { Разность между оценкой одышки, даваемой больным, } \\
\text { и установленной врачом по шкале mMRC, } M \pm S D\end{array}$ & $-0,523 \pm 0,762$ & $-0,801 \pm 0,679$ & 0,076 & 0,050 & 0,762 \\
\hline Преимущественно эмфизематозный фенотип, $n$ (\%) & $6(13,6)$ & $18(43,9)$ & 0,002 & 0,026 & 0,001 \\
\hline Преимущественно бронхитический фенотип, $n$ (\%) & $21(47,7)$ & $9(22,0)$ & 0,011 & 0,023 & 0,105 \\
\hline$O \Phi B_{1}, \%, M \pm S D$ & $51,900 \pm 17,604$ & $52,900 \pm 16,199$ & 0,773 & 0,621 & 0,669 \\
\hline \multicolumn{6}{|l|}{$\begin{array}{l}\text { Стадия ХОБл (GOLD 2008) или степень ограничения } \\
\text { бронхиальной проходимости (GOLD 2011), } n \text { (\%): }\end{array}$} \\
\hline I (легкая) & $2(4,5)$ & $0(0)$ & 0,265 & 0,36 & 0,661 \\
\hline II (среднетяжелая) & $21(47,7)$ & $23(56,1)$ & 0,29 & 0,57 & 0,65 \\
\hline III (тяжелая) & $15(34,1)$ & $12(29,3)$ & 0,404 & 0,546 & 0,129 \\
\hline IV (крайне тяжелая) & $6(13,6)$ & $6(14,6)$ & 0,57 & 0,507 & 0,615 \\
\hline \multicolumn{6}{|l|}{ Легочное сердце: } \\
\hline нет & $11(25,0)$ & $6(14,6)$ & 0,178 & 0,388 & 0,801 \\
\hline компенсация / субкомпенсация & $28(63,6)$ & $29(70,7)$ & 0,322 & 0,453 & 0,275 \\
\hline декомпенсация & $5(11,4)$ & $6(14,6)$ & 0,449 & 0,556 & 0,385 \\
\hline Частота обострений в год, $M \pm S D$ & $1,780 \pm 1,008$ & $2,000 \pm 1,061$ & 0,339 & 0,463 & 0,350 \\
\hline Число пациентов, имеющих $\geq 2$ обострений в год, $n$ (\%) & $15(34,1 \%)$ & $24(58,5 \%)$ & 0,038 & 0,06 & 0,124 \\
\hline Сатурация кислородом, \% ( \pm SD) & $93,400 \pm 3,046$ & $93,530 \pm 3,471$ & 0,699 & 0,993 & 0,687 \\
\hline Число умерших за время проведения исследования, $n$ (\%) & $5(11,4)$ & $1(2,4)$ & 0,118 & 0,063 & 0,693 \\
\hline
\end{tabular}


Предикторы дезадаптивных типов реагирования у пациентов с ХОБЛ

\begin{tabular}{|c|c|c|}
\hline Критерий & Гипонозогнозия & Тревога о болезни и депрессия \\
\hline Возраст, годы & $\approx 60$ & $\approx 70$ \\
\hline Образование & Среднее & Высшее \\
\hline Трудовая деятельность & Сохраняется & Прекращается \\
\hline Курение & Злостное & Без особенностей \\
\hline Профессиональные вредности & Есть & Нет (устранены) \\
\hline ОРЗ в анамнезе & Редко & Часто \\
\hline $\begin{array}{l}\text { Длительность ХОБЛ по сравнению со временем существования } \\
\text { симптомов }\end{array}$ & Значимо меньше & Примерно одинаковы \\
\hline Фенотип ХОБЛ & Преимущественно бронхитический & Преимущественно эмфизематозный \\
\hline Оценка симптомов & Преуменьшение & Преувеличение \\
\hline Обострения с точки зрения пациента & Редкие & Частые \\
\hline Сочетание с БА & Редко & Часто \\
\hline Сердечно-сосудистые катастрофы в анамнезе & Часто & Редко \\
\hline
\end{tabular}

ней без участия психолога и психиатра может уже при первой встрече с пациентом предугадать дальнейшее его поведение в болезни: относительно молодой, злостно курящий пациент со средним специальным образованием, продолжающий работать на вредном производстве, описывающий свое здоровье как крепкое, немного ухудшившееся в связи с появлением незначительной одышки и кашля, присутствующего на протяжении уже многих лет, усиливающегося при редких простудных заболеваниях, при обследовании которого выявляются одышка уже при раздевании / одевании, преимущественно бронхитический фенотип ХОБЛ, признаки перенесенного в прошлом острого ИМ и поражения артерий нижних конечностей, вероятнее всего, будет отнесен к дезадаптивному типу реагиривания на ХОБЛ - гипонозогнозии. Пациент же более старшего возраста с высшим образованием, находящийся на пенсии и инвалидности, ранее работавший на вредном производстве, однако прекративший этот вид деятельности с появлением первых симптомов, с частыми ОРЗ и часто обращающийся к врачу, преувеличивающий выраженность одышки, имеющий преимущественно эмфизематозный вариант ХОБЛ, сочетанный с БА, с большей долей вероятности может быть отнесен к категории больных с тревогой о болезни и требует особой настороженности в отношении развития ТДР.

\section{Заключение}

Среди больных ХОБЛ, помимо тревоги и депрессии, широко распространен недостаточно изученный дезадаптивный тип реагирования на заболевание - гипонозогнозия, или аберрантная ипохондрия, существенно отличающийся по поведению в болезни при тревоге о болезни и депрессии. Проведено сопоставление типов реагирования с особенностями формирования и течения ХОБЛ и социодемографическими характеристиками пациентов. У больных с тревогой и депрессией, как и у пациентов с гипонозогнозией, выявлены характерные предикторы, позволяющие прогнозировать формирование этих типов реагирования на заболевание. Перечисленные параметры могут лечь в основу критериев дальнейшего выбора персонифицированных реабилитационных мероприятий для конкретного больного, основным направлением которых служит коррекция дезадаптивных черт поведения в болезни.

\section{Литература / References}

1. Global Initiative for Chronic Obstructive Lung Diseases. Global Strategy for the Diagnosis, Management and Prevention of Chronic Obstructive Pulmonary Disease. (Revised 2011, 2013, 2014). Глобальная стратегия диагностики, лечения и профилактики хронической обструктивной болезни легких. Пересмотр 2011 г.: Перевод с англ. под ред. А.С.Белевского. М.: РРО; 2012. / Global Strategy of Diagnosis, Treatment and Prevention of Chronic Obstructive Pulmonary Disease (updated 2011). [Global'naya strategiya diagnostiki, lecheniya i profilaktiki khronicheskoy obstruktivnoy bolezni legkikh. Peresmotr 2011 g.]: Belevsky A.S. (editor of Russian version). Moscow; Russian Respiratory Society; 2012 (in Russian).

2. Arayal S., Diaz-Guzman E., Manino D.M. Prevalence of COPD and comorbidity. Eur. Respir. Monogr. 2013; 59: 1-12.

3. Cafarella P.A., Effing T.W., Usmani Z.-A., Frith P.A. Treatments for anxiety and depression in patients with COPD: a literature review. Respirology 2012; 17: 627-638.

4. Hill K., Geist R., Goldstein R.S., Lacasse Y. Anxiety and depression in end-stage COPD. Eur. Respir. J. 2008; 31: 667-677.

5. Hynninen K.M., Breitve M.H., Wiborg A.B. et al. Psychological characteristics of a patients with chronic obstructive pulmonary disease: a review. J. Psychosom. Res. 2005; 59 (6): 429-443.

6. Yohannes A.M., Willgoss T.G., Baldwin R.C., Connolly M.J. Depression and anxiety in chronic heart failure and chronic obstructive pulmonary disease: prevalence, revalence, clinical implication and management principles. Int. J. Geriatr. Psychiatry. 2010; 25 (12): 1209-1221.

7. Ахмедова О.С. Качество жизни пациентов с хронической обструктивной болезнью легких. Известия Российского государственного университета им. А.И.Герцена "Аспирантские тетради" 2007; 22 (53): 266-270. / Akhmedova O.S. Quality of life in patients with chronic obstructive pulmonary disease. Izvestia Rossiyskogo gosudarstvennogo universiteta im. A.I.Gerstena "Aspirantskye tetradi". 2007; 22 (53): 266-270 (in Russian). 
8. Кулганов В.А., Белов В.Г., Парфенов Ю.А. Основы клинической психологии: Учебник для вузов. Стандарт третьего поколения. СПб: Питер; 2012. / Kulganov V.A., Belov V.G., Parfenov Yu.A. Basics of Clinical Psychology: Textbook for High School Students. The 3rd Generation Standard. [Osnovy Klinicheskoy Psikhologii: Uchebnik Dlya Vuzov. Standart Tret'ego Pokoleniya]. S.Petersburg: Piter; 2012 (in Russian).

9. Смулевич А.Б., Волель Б.А. Расстройства личности и соматическая болезнь (проблема ипохондрического развития личности). Журнал невропатологии и психиатрии им. С.С.Корсакова. 2008; 5: 4-12. / Smulevich A.В., Volel B.A. Personality disorders and somatic disease (a problem of personality hypochondriac development). Zhurnal Nevrologii i Psikhiatrii im. S.S.Korsakova. 2008; 5: 4-12 (in Russian).

10. Соловьева Э.Ю. Тревожные расстройства в общей медицинской практике. Consilium Medicum 2008; 10 (2): 122-128. / Solovyeva E.Yu. Anxiety disorders in general medical practice. Consilium Medicum. 2008; 10 (2): 122-128 (in Russian).

11. Ресурсы официального сайта Всемирной организации здравоохранения. www.who.int/topics/depression/ru/ An official website of World Health Organization www.who.int/ topics/depression/ru
12. Смулевич А.Б. Депрессии в общей медицине. М.: Медицинское информационное агентство; 2001. / Smulevich A.B. Depression in general medicine [Depressii $\mathrm{v}$ obshchey meditsine]. Moscow; Medical Information Agency; 2001 (in Russian).

13. Овчаренко С.И., Галеикайте Я.К., Волель Б.А. и др. Типология расстройств личности и реагирования на заболевание при хронической обструктивной болезни легких. Пульмонология. 2013; 2: 74-80. / Ovcharenko S.I., Galetskayte Ya.K., Volel' B.A. et al. Typology of personality disorders and responses to a disease in patients with chronic obstructive pulmonary disease. Pul'monologiya. 2013; 2: 74-80 (in Russian).

\section{Информация об авторах}

Овчаренко Светлана Ивановна - д. м. н., профессор кафедры факультетской терапии № 1 лечебного факультета ГБОУ ВПО "Первый МГМУ им. И.М.Сеченова"; тел.: (499) 248-56-67; e-mail: svetftk@mail.ru

Галецкайте Янина Казисовна - аспирант кафедры факультетской терапии № 1 лечебного факультета ГБОУ ВПО "Первый МГМУ им. И.М.Сеченова"; тел.: (499) 248-56-67; e-mail: galetskayte@gmail.com

Волель Беатриса Альбертовна - д. м. н., профессор кафедры психиатрии и психосоматики ИПО ГБОУ ВПО "Первый МГМУ им. И.М.Сеченова"; тел.: (499) 616-51-01; e-mail: beatrice.volel@gmail.com

Поступила 07.04.14 (ККоллектив авторов, 2014 УДК 616.24-036.12-06 